DOI: https://doi.org/10.47405/mjssh.v6i8.944

\begin{tabular}{|c|c|}
\hline 4 & Malaysian Journal of Social Sciences and Humanities (MJSSH) \\
\hline $\begin{array}{l}\text { Malaysian Juoural of } \\
\text { Social ccciecces and }\end{array}$ & Volume 6, Issue 8, August 2021 \\
\hline (MJ-sSH) & e-ISSN : 2504-8562 \\
\hline & $\begin{array}{l}\text { Journal home page: } \\
\text { www.msocialsciences.com }\end{array}$ \\
\hline
\end{tabular}

\title{
Night Eating Syndrome and Its Association with Sleep Quality and Body Mass Index Among University Students During the Covid-19
}

\author{
Yong Qi Kwan' ${ }^{1}$, Siew Siew Lee ${ }^{1}$, Shi-Hui Cheng ${ }^{1}$ \\ ${ }_{1}^{1}$ School of Biosciences, Faculty of Science and Engineering, University of Nottingham Malaysia, Jalan Broga, \\ 43500 Semenyih, Selangor Darul Ehsan, Malaysia.
}

Correspondence: Shi-Hui Cheng (ShiHui.Cheng@nottingham.edu.my)

\begin{abstract}
Night eating syndrome (NES) is a disordered eating behaviour characterized by hyperphagia at night and is often accompanied by a sleep disturbance. This study aims to determine the prevalence of NES and its association between sleep quality and body mass index (BMI) among the private university students during the Covid-19. A total of 166 students from a private university participated in this cross-sectional study. Online self-administered questionnaires were used to collect and determine socio-demographic data, BMI, NES, and sleep quality. NES was assessed using Night Eating Diagnostic Questionnaire (NEDQ) while sleep quality was assessed using Pittsburgh Sleep Quality Index Questionnaire (PSQI). The results showed that 38.6\% of the participants were engaging with NES, $45.2 \%$ were having poor sleep quality and $25.9 \%$ were overweight or obese during the Covid-19. There were significant associations between NES with sleep quality and BMI, which students with NES were found to have poorer sleep quality $(r=0.306, p<0.001)$ and higher BMI $(r=0.024, p=0.763)$. In addition, poor sleep quality was found to be positively associated with BMI ( $\mathrm{r}=0.161, \mathrm{p}=0.038)$. Males $(\mathrm{AOR}=2.198,95 \% \mathrm{CI}=1.005-4.808)$ and poor sleepers $(\mathrm{AOR}=1.176,95 \% \mathrm{CI}=1.028-1.346)$ were the risk factors of NES. In conclusion, the prevalence of NES, poor sleep quality, and overweight and obesity were at an alarming rate. NES was found to be related to both poorer sleep quality and higher BMI among the students. Therefore, interventions such as behavioural and cognitive therapy should be implemented to promote healthy eating behaviour among university students.
\end{abstract}

Keywords: night eating syndrome, sleep quality, body mass index, university students, Covid-19

\section{Introduction}

In the past years, due to the growing trend in eating disorders, different type of eating disorders has become one of the global concerns and have gotten much attention from the healthcare industry (Pike \& Dunne 2015). One of the eating disordered that relates to sleep quality is night eating syndrome (NES). NES is characterized by sleep disordered and overeats during the night-time (between the evening meal and sleeping time) at least twice a week (Shillito et al., 2018). Night eating syndrome (NES) was first described by Stunkard et al. (1955) in an obese, 18 years old lady who has been overeating and gaining weight. In 1992, a more formal definition of NES was then improvised as "morning anorexia, evening hyperphagia, and insomnia" (Stunkard, 1992). Later in 2010, Allison et al. then described NES as a "delay in the circadian timing of food intake". NES is characterized by consumption of at least $25 \%$ of the total daily caloric intake after the evening meal and before sleeping or at least two episodes of nocturnal eating per week (Allison et al., 2010). In addition, a NES patient 
must fulfil at least three descriptors including (i) lack of appetite in the morning, (ii) having a strong urge to eat after dinner and before sleeping, (iii) insomnia at least four nights a week, (iv) the belief that one must eat to get sleep, and (v) depressed mood or mood which gets worse in the evening and/or night-time (Allison et al., 2010; Runfola et al., 2014).

In the United States, $12.3 \%$ of university students from Michigan University were found to be engaging with NES (Yahia et al., 2017). Previous studies have reported a high prevalence of NES among the university students in Malaysia (Gan et al., 2019; Sarina and Poh, 2015). This could be due to high stress, peer pressure, emotional eating, and sleep disturbance (Gan et al., 2019; He et al., 2018). In Malaysia, $12.2 \%$ of the university students from a public university were found to be having NES, and more than half $(55.1 \%)$ of the participants were found to have poor sleeping quality (Gan et al. 2019). Another study by Sarina and Poh (2015) found that $23.4 \%$ of the university students from Shah Alam, Selangor were engaging with NES.

University students with poor sleep quality were found to have a higher NES score (Akdevelioglu et al. 2020). Students with NES were reported tend to have shorter sleep time (Yahia et al., 2017). On the other hand, in studies that considering the association between NES and Body Mass Index (BMI), most studies found that NES was positively associated with higher BMI. However, Yahia et al. (2017) demonstrated contradicting results, in which there was no association between NES and BMI among undergraduate students from Central Michigan University. Moreover, according to a review paper done by Bruzas and Allison (2019), out of a total of 11 studies published from December 2013 to February 2019, five of these studies have suggested that there was a positive relationship between NES and BMI, five suggested that there was no relationship, and one reported that there were mixed findings. The previous findings regarding the association between NES and BMI were inconsistent, hence this study aims to determine the association and thus provide a clearer direction to tackle the problem of NES.

The individuals with NES may have no control over the amount of food they eat while some may continue eating even when they are already full (Gluck et al., 2001). This can lead to excessive calorie intake, hence causing overweight or obesity and subsequently the obesity related complications such as cardiovascular disease, diabetes and other non-communicable diseases. On the other hand, the NES patients may feel embarrassed or guilty by the amount they eat, thus causing them to have a negative self-image, and leads to depression or anxiety. NES severity was significantly correlated with psychological distress, namely depression, anxiety, and stress (He et al., 2018). Stress will also affect the food intake among the university students (Cheng \& Mohd Kamil 2020). This suggests the potential negative impact between NES and obesity.

Coronavirus 2019 (Covid-19) pandemic has brought changes to the eating behaviour. Lockdown measurement that was implemented by the government to prevent the spread of the Covid-19 has resulted in the changes in the lifestyle of the university students. The closure of the university, online teachings, constrains in outdoors and a lack of social activities may have a negative impact on eating behaviour (Cao et al. 2020). Previous researches focused on the prevalence of NES among students in public university (Gan et al., 2019; Sarina and Poh, 2015). Nonetheless, the prevalence of NES among students in private university especially during the Covid-19 remains unclear. Hence, this study aims to determine the prevalence of NES and the association between NES, sleep quality and BMI among the students of a private university during the Covid-19.

\section{Methodology}

\section{Study design, sample size and subjects}

A cross-sectional online study was conducted among the students at a private university from November 2020 to January 2021. The sample size of this study was calculated using the formula by Daniel (1999). Using an estimated prevalence of $12 \%$ (Gan et al. 2019) and precision of 5\% (E=0.05) with $95 \%$ confidence interval $(\mathrm{Z}=1.96)$, the sample required was 162 participants. University students 
were invited to participate by sending email through snowball methods and social media. The inclusion criteria in the study were undergraduate students aged above 18 years, and the exclusion criteria were those who are pregnant, taking any medications, and having serious physical or mental diseases.

This study was approved by the Science and Engineering Research Ethics Committee of the university (SEREC reference: KYQ101020). An online consent form was obtained from each participant prior to the data collection.

\section{Data Collection}

All data collection was performed through Google Forms, on a self-reporting basis. Data collected including the participants' sociodemographic characteristics, anthropometric data, NES, and sleep quality.

\section{Part A: Sociodemographic Characteristics and Anthropometric Measurement}

Sociodemographic data including the name, age, gender, ethnicity, current year of study, faculty of study course and weekly allowance were collected. In addition, participants were required to selfreport their body weight measured in kilograms $(\mathrm{kg})$ and height measured in meters $(\mathrm{m})$. The body mass index (BMI) of each participant was calculated and categorised based on the World Health Organization (WHO) guidelines-Asia-Pacific classification of BMI (World Health Organization, 2004). A BMI less than $18.5 \mathrm{~kg} / \mathrm{m} 2$ was classified as underweight, BMI at or greater than $18.5 \mathrm{~kg} / \mathrm{m} 2$ and less than $22.9 \mathrm{~kg} / \mathrm{m} 2$ was normal weight, overweight had a BMI at or greater than $23.0 \mathrm{~kg} / \mathrm{m} 2$, and a BMI at or over $27.5 \mathrm{~kg} / \mathrm{m} 2$ was considered as obesity.

\section{Part B: Night Eating Syndrome Criteria and Questionnaire}

The Night Eating Diagnostic Questionnaire (NEDQ) validated by Nolan and Geliebter (2017), was used to assess NES symptoms. A total of 19 questions were assessed and among the questions, six criteria categories were classified for the hierarchical score. The criteria category I was to screen out the participants who showed at least mild NES symptoms by determining the daily eating pattern through the prevalence of night eating throughout a week (more than 2 times a week) with the percentage of food eaten at night (more than $25 \%$ of total caloric intake) and the prevalence of nocturnal eating disorder (more than twice a week for more than three months) (Birketvedt et al., 1999; Nolan and Geliebter, 2016). The criteria category II was to determine the awareness of night eating and nocturnal eating episodes and the criteria category III was to assess the behavioural and psychological symptoms of NES, including lack of appetite in the morning, evening hyperphagia, sleep disturbance, or insomnia (Allison et al., 2008; Stunkard et al., 1955), the presence of a belief that one must eat to sleep and mood that worsen in the evening or mood that is frequently depressed (Nolan and Geliebter, 2016). Category IV was to identify the significant distress and/or impairment in functions, category $\mathrm{V}$ was to determine whether the current eating habit has been maintained for more than three months and category VI was to assess the other stress factors such as medical disorder, medication, or other psychiatric disorder, which may contribute to the eating habits.

Based on the hierarchical scores obtained from the number of symptoms shown, all participants were categorized into four different groups: non-night eater, mild night eater, moderate night eater, and fullsyndrome night eater based on their NES severity (Lundgren et al., 2012). Participants who did not meet any criteria were categorized as non-night eaters (normal) and participants who only met the criteria category I were classified as mild night eaters. Participants who met category I and at least three of the criteria in category III were known as moderate night eaters while participants who met the criteria categories I, III (at least 3 criteria were met), IV, and V were diagnosed as full syndrome NES.

\section{Part C: Sleeping Quality Questionnaire}


The Pittsburgh Sleep Quality Index Questionnaire (PSQI) was used to evaluate the sleeping pattern and quality of each participant based on the past one month period (Buysse et al., 1989). This selfreporting questionnaire has been validated by Dietch et al. (2016). A total of 19 self-rated questions were asked and scores obtained were summed to yield the global score. By answering the questionnaire, the seven sleep components: sleep latency, sleep duration, habitual sleep efficiency, sleep disturbances, use of sleeping medication, and daytime dysfunction were measured based on the participants' self-reported retrospective evaluation (Buysse et al., 1989). The range of score for each component was from 0 to 3, leading to a global PSQI score of 0 to 21. According to the total score obtained, the sleeping quality of the participants was evaluated with the range of points, from no difficulty in sleep to severe difficulties in sleeping as the points ascend. The participants were then categorized by the PSQI global scores, where PSQI score $\leq 5$ was classified as good sleep quality, while PSQI score $>5$ was classified as poor sleep quality.

\section{Part D: Factors That Cause Habit of Night Eating}

Variables that had a p-value $<0.25$ in the chi-square test were selected as a possible risk factor and included in the final logistic regression to determine the risk factors associated with NES.

\section{Statistical Analysis}

The collected data were analysed using the IBM SPSS Statistics version 25.0 (IBM Corp., Armonk, NY, USA). All the continuous variables were described as mean and standard deviations and categorical variables were described as number and proportions. Chi-square test and independent t-test were used to compare variables among NES and non-NE groups, while the Pearson correlation test was carried out to analyse the associations between NES, sleep quality, and BMI of the students. A binary logistic regression test was performed to determine the risk factors associated with NES. The significance level was set at $\mathrm{p}<0.05$.

\section{Result}

\section{Prevalence of NES}

The results show that $38.6 \%$ of the participants were found to be engaging with NES (Table 1). Of 64 participants who were engaged in NES, $22.9 \%$ were found to have mild symptoms of NES, $10.2 \%$ were in the moderate-NES group and 5.5\% were in the full-syndrome NES group.

Table 1: The prevalence of NES among university students

\begin{tabular}{ll}
\hline Grouping & $\mathbf{n}(\%)$ \\
\hline Non-NE Group & $102(61.4)$ \\
NES Group & $64(38.6)$ \\
Mild NES & $38(22.9)$ \\
Moderate NES & $17(10.2)$ \\
Full NES & $9(5.5)$ \\
\hline
\end{tabular}

\section{Sociodemographic Characteristics}

A total of 166 students with a mean age of $21 \pm 1.2$ years were recruited in this study. The sociodemographic characteristics of the participants by their night eating diagnostic status are shown in Table 2. The majority of the participants were Chinese (77.1\%), followed by Indian (9.1\%), Malays (8.4\%), and the other ethnicities (5.4\%) including Sikh, Korean, Punjabi, African, Canadian, Kazakh, Mauritian Creole, and Burmese. About $48.2 \%$ of the participants were Year 3 students and $41.6 \%$ of the participants were from the faculty of Science. With regards to the economic status, $69.9 \%$ of the participants were having less than RM200 for their weekly allowance. Also, 27.7\% of the participants 
were attempting to lose weight while $19.3 \%$ were physically active (exercise more than 4 times a week).

As shown in Table 2, the prevalence of a few psychological and behavioural characteristics of NES are higher in the NES group than the non-NE group: evening hyperphagia $(51.3 \%)$ and belief that one must eat to fall asleep (87.5\%).Besides, almost half (45.2\%) of the participants were found to have poor sleep quality.

Our results revealed that gender $(\mathrm{p}=0.002)$ was significantly associated with NES. About $51.3 \%$ of the male participants were found to be engaging with NES while a lower prevalence of NES (27.3\%) was found among the female participants. Participants who got more than RM200 for their weekly allowance $(50 \%)$ were found to have a higher risk to NES ( $\mathrm{p}=0.047)$. Also, the prevalence of NES among the participants with evening hyperphagia $(51.3 \%)$ was significantly higher $(\mathrm{p}=0.002)$ than the participants who do not have the urge to eat $(27.3 \%)$ during night-time, while the Pittsburgh sleep quality score of the NES participants $(6.4 \pm 3.2)$ was significantly higher $(\mathrm{p}=0.012)$ compared to the non-NE group $(5.1 \pm 2.8)$.

Table 2: Sociodemographic characteristics of the participants by the night eating diagnostic status

\begin{tabular}{|c|c|c|c|c|}
\hline Variable & $\begin{array}{c}\text { Total } \\
(\mathrm{N}=166) \\
n(\%)\end{array}$ & $\begin{array}{c}\text { Non-NE } \\
(\mathrm{N}=102) \\
\mathrm{n}(\%)\end{array}$ & $\begin{array}{c}\text { NES } \\
(\mathrm{N}=64) \\
\mathrm{n}(\%)\end{array}$ & p-value \\
\hline Gender & & & & $0.002^{\mathrm{b} *}$ \\
\hline Male & $78(47.0)$ & $38(48.7)$ & $40(51.3)$ & \\
\hline Female & $88(53.0)$ & $64(72.7)$ & $24(27.3)$ & \\
\hline Age (years) $($ Mean \pm SD) & $21.0 \pm 1.2$ & $21.1 \pm 1.2$ & $20.9 \pm 1.2$ & $0.362^{\mathrm{a}}$ \\
\hline Ethnicity & & & & $0.089^{\mathrm{b}}$ \\
\hline Malay & $14(8.4)$ & $7(50.0)$ & $7(50.0)$ & \\
\hline Chinese & $128(77.1)$ & $77(60.2)$ & $51(39.8)$ & \\
\hline Indian & $15(9.1)$ & $9(60.0)$ & $6(40.0)$ & \\
\hline Others & $9(5.4)$ & $9(100.0)$ & 0 & \\
\hline Year of study & & & & $0.552^{\mathrm{b}}$ \\
\hline Foundation & $6(3.6)$ & $3(50.0)$ & $3(50.0)$ & \\
\hline Year 1 & $34(20.5)$ & $23(67.6)$ & $11(32.4)$ & \\
\hline Year 2 & $43(25.9)$ & $25(58.1)$ & $18(41.9)$ & \\
\hline Year 3 & $80(48.2)$ & $48(60.0)$ & $32(40.0)$ & \\
\hline Year 4 & $3(1.8)$ & $3(100.0)$ & 0 & \\
\hline Faculty & & & & $0.119^{\mathrm{b}}$ \\
\hline Arts and Social Sciences & $36(21.7)$ & $27(75.0)$ & $9(25.0)$ & \\
\hline Engineering & $55(33.1)$ & $28(50.9)$ & $27(49.1)$ & \\
\hline Science & 69 (41.6) & $44(63.8)$ & $25(36.2)$ & \\
\hline Foundation & $6(3.6)$ & $3(50.0)$ & $3(50.0)$ & \\
\hline \multicolumn{5}{|l|}{ Weekly Allowance } \\
\hline Less than RM200 & $116(69.9)$ & $77(66.4)$ & $39(33.6)$ & $0.047^{\mathrm{b} *}$ \\
\hline RM200 or more & $50(30.1)$ & $25(50.0)$ & $25(50.0)$ & \\
\hline Dieting to lose weight & & & & $0.536^{\mathrm{b}}$ \\
\hline Yes & $46(27.7)$ & $30(65.2)$ & $16(34.8)$ & \\
\hline No & $120(72.3)$ & $72(60.0)$ & $48(40.0)$ & \\
\hline Physical activity & & & & $0.177^{\mathrm{b}}$ \\
\hline Active ( $\geq 5$ times/week) & $32(19.3)$ & 23 (71.9) & $9(28.1)$ & \\
\hline Inactive ( $<5$ times/week) & $134(80.7)$ & $79(59.0)$ & $55(41.0)$ & \\
\hline Self-reported stress rate & & & & $0.331^{\mathrm{b}}$ \\
\hline Mild & $8(4.8)$ & $5(62.5)$ & $3(37.5)$ & \\
\hline Moderate & $69(41.6)$ & $43(62.3)$ & $26(37.7)$ & \\
\hline Severe & $72(43.4)$ & $47(65.3)$ & $25(34.7)$ & \\
\hline
\end{tabular}


DOI: https://doi.org/10.47405/mjssh.v6i8.944

\begin{tabular}{|c|c|c|c|c|}
\hline Extremely Severe & $17(10.2)$ & $7(41.2)$ & $10(58.8)$ & \\
\hline Morning Anorexia & & & & $0.279^{\mathrm{b}}$ \\
\hline Yes & $54(32.5)$ & $30(55.6)$ & $24(44.4)$ & \\
\hline No & $112(67.5)$ & $72(64.3)$ & $40(35.7)$ & \\
\hline Breakfast per week & & & & $0.177^{\mathrm{b}}$ \\
\hline Less than 4 times & $85(51.2)$ & $48(56.5)$ & $37(43.5)$ & \\
\hline 4 times or more & $81(48.8)$ & $54(66.7)$ & $27(33.3)$ & \\
\hline Evening Hyperphagia & & & & $0.002^{\mathrm{b} *}$ \\
\hline Yes & $78(47.0)$ & $38(48.7)$ & $40(51.3)$ & \\
\hline No & $88(53.0)$ & $64(72.7)$ & $24(27.3)$ & \\
\hline Depressed nearly everyday & & & & $0.802^{\mathrm{b}}$ \\
\hline Yes & $50(30.1)$ & $30(60.0)$ & $20(40.0)$ & \\
\hline No & $116(69.9)$ & $72(62.1)$ & $44(37.9)$ & \\
\hline Mood lowered in the evening/night & & & & $0.129^{\mathrm{b}}$ \\
\hline Yes & $46(27.7)$ & $24(52.2)$ & $22(47.8)$ & \\
\hline No & $120(72.3)$ & $78(65.0)$ & $42(35.0)$ & \\
\hline $\begin{array}{l}\text { Belief that one must eat to fall } \\
\text { asleep }\end{array}$ & & & & $0.004^{\mathrm{b} *}$ \\
\hline Yes & $8(4.8)$ & $1(12.5)$ & $7(87.5)$ & \\
\hline No & $158(95.2)$ & $101(63.9)$ & $57(36.1)$ & \\
\hline $\begin{array}{l}\text { Sleep onset or maintenance } \\
\text { Insomnia }\end{array}$ & & & & $0.659^{\mathrm{b}}$ \\
\hline Yes & $41(24.7)$ & $24(58.5)$ & $17(41.5)$ & \\
\hline No & $125(75.3)$ & $78(62.4)$ & $47(37.6)$ & \\
\hline $\begin{array}{l}\text { Pittsburgh Sleep Quality Score } \\
(\text { Mean } \pm S D)\end{array}$ & $5.6 \pm 3.0$ & $5.1 \pm 2.8$ & $6.4 \pm 3.2$ & $0.012^{\mathrm{b} *}$ \\
\hline Good & $91(54.8)$ & $61(67.0)$ & $30(33.0)$ & $0.103^{\mathrm{b}}$ \\
\hline Poor & $75(45.2)$ & $41(54.7)$ & $34(45.3)$ & \\
\hline
\end{tabular}

Independent $\mathrm{t}$-tes $\mathrm{t}^{\mathrm{a}}$ was performed with a significant difference at $* \mathrm{p}<0.05$

Chi-square test ${ }^{\mathrm{b}}$ was performed with significant differences at $* \mathrm{p}<0.05$ and $* * * \mathrm{p}<0.001$

Notes. Others under Ethnicity includes Sikh, Korean, Punjabi, African, Canadian, Kazakh, Mauritian Creole, and Burmese.

\section{Anthropometry Characteristics by Night Eating Diagnostic Status}

Table 3 shows the anthropometry measurements of the participants by night eating diagnostic status. About $25.9 \%$ of the participants were either overweight or obese. Although the prevalence of overweight and obesity in the NES group was slightly more than the non-NES group, no significant differences $(p=0.362$ ) were found. There were no significant differences between NES with weight, height, and BMI.

Table 3: Anthropometric measurement of the participants by the night eating diagnostic status

\begin{tabular}{|c|c|c|c|c|}
\hline Anthropometric & $\begin{array}{l}\text { Total } \\
(\mathrm{N}=166) \\
\text { n }(\%)\end{array}$ & $\begin{array}{l}\text { Non-NE } \\
(\mathrm{N}=102) \\
\mathrm{n}(\%)\end{array}$ & $\begin{array}{l}\text { NES } \\
(\mathrm{N}=64) \\
\mathrm{n}(\%)\end{array}$ & p-value \\
\hline Height (m) $($ Mean \pm SD $)$ & $1.7 \pm 9.6$ & $1.7 \pm 0.1$ & $1.7 \pm 0.9$ & $0.125^{\mathrm{a}}$ \\
\hline Weight (kg) $($ Mean \pm SD) & $61.0 \pm 16.6$ & $59.3 \pm 16.2$ & $63.7 \pm 17.0$ & $0.097^{\mathrm{a}}$ \\
\hline BMI $\left(\mathbf{k g} / \mathbf{m}^{2}\right)($ Mean \pm SD) & $21.6 \pm 4.2$ & $21.2 \pm 3.9$ & $22.3 \pm 4.6$ & $0.126^{\mathrm{a}}$ \\
\hline BMI status & & & & $0.362^{b}$ \\
\hline Underweight & $33(19.9)$ & $23(69.7)$ & $10(30.3)$ & \\
\hline Normal & $90(54.2)$ & $57(63.3)$ & $33(36.7)$ & \\
\hline Overweight & $30(18.1)$ & $16(53.3)$ & $14(46.7)$ & \\
\hline Obese & $13(7.8)$ & $6(46.2)$ & $7(53.8)$ & \\
\hline
\end{tabular}

Independent $\mathrm{t}$-tes $\mathrm{t}^{\mathrm{a}}$ was performed with a significant difference at $* * * \mathrm{p}<0.001$

Chi-square test ${ }^{\mathrm{b}}$ was performed with significant differences at $* * \mathrm{p}<0.01$ and $* * * \mathrm{p}<0.001$ 


\section{The Association between NES status, Pittsburgh Sleep Quality Scale, and BMI among the university students}

The associations between the night eating diagnostic status, PSQI global score, and BMI were shown in table 4. There was a significant positive moderate correlation $(r=0.31, p<0.001)$ between the NES status and PSQI score and a significant weak correlation $(\mathrm{r}=0.161, \mathrm{p}=0.038)$ between $\mathrm{BMI}$ and night eating diagnostic score. The mean BMI and standard deviations of the participants by sleep quality were shown in table 5. The mean BMI of the poor sleepers is slightly higher than the good sleepers but no significant difference $(\mathrm{p}=0.316)$ was found between the two groups.

Table 4: The correlation coefficient between the NES status, Pittsburgh sleep quality scale, and BMI

\begin{tabular}{llll}
\hline & NES Status & PSQS & BMI \\
\hline NES Status & 1 & & \\
PSQS & $0.306^{* *}$ & 1 & 1 \\
BMI & $0.161 *$ & 0.024 &
\end{tabular}

Pearson's Correlation Coefficient was performed with significance levels of $* \mathrm{p}<0.05$ and $* * \mathrm{p}<0.01$

Table 5: The mean BMI and standard deviations of the participants by sleep quality

\begin{tabular}{lll}
\hline Variable & BMI $($ Mean \pm SD) & p-value \\
\hline Good Sleeper $(\mathbf{N}=\mathbf{9 1})$ & $21.3 \pm 4.1$ & 0.316 \\
Poor Sleeper $(\mathbf{N}=\mathbf{7 5})$ & $22.0 \pm 4.4$ & \\
\hline Independent t-test was performed with a significant difference at *p<0.05
\end{tabular}

\section{Factors associated with NES}

Based on the logistic regression analysis shown in table 6, the factors associated with NES were gender and sleep quality. Males were found to have 2 times higher risk $(\mathrm{AOR}=2.198,95 \% \mathrm{CI}=1.005$ 4.808) to be engaged in NES than females. For the Pittsburgh sleep quality global score increases by 1 , the probability that the participants will be a member of the NES group increased by $1.176(95 \% \mathrm{CI}=$ 1.028-1.346) times. NES was not associated with ethnicity, faculty, weekly allowance, physical activity, breakfast per week, evening hyperphagia, and BMI.

Table 6: The binary logistic regression results of the possible risk factors

\begin{tabular}{lcc}
\hline Variables & $\begin{array}{c}\text { Adjusted Odds Ratio } \\
(\mathbf{9 5 \%} \mathbf{C I})\end{array}$ & p-value \\
\hline Gender & 1 & \\
Female & $2.198(1.005-4.808)$ & $0.049 *$ \\
Male & 1 & \\
Ethnicity & $1.780(0.707-4.484)$ & 0.221 \\
Non-Chinese & 1 & \\
Chinese & $1.370(0.515-3.647)$ & 0.528 \\
Faculty & & \\
Foundation and Engineering & & \\
Science & & \\
Arts and Social Sciences & & \\
Weekly Allowance & $2.077(0.757-5.700)$ & \\
& &
\end{tabular}


Less than RM200

1

RM200 or more

$1.438(0.672-3.081)$

0.350

Physical Activity

Active ( $\geq 5$ times a week)

1

Inactive ( $<5$ times a week)

$1.654(0.646-4.234)$

0.294

Breakfast per week

4 times or more

1

Less than 4 times

$1.198(0.596-2.407)$

0.612

Evening Hyperphagia

1.965 (0.961-4.017)

0.064

Pittsburgh Sleep Quality Scale

$1.176(1.028-1.346)$

$0.019 *$

BMI

1.044 (0.958-1.138)

0.323

Binary logistic regression test was performed with a significant difference at $* \mathrm{p}<0.05$

\section{Discussion}

\section{Prevalence of NES among the University Students}

In this study, $38.6 \%$ of the students were found to be engaged with NES. As compared to the past studies, the result found in this study was alarming. The prevalence of NES found in this study was higher than the results reported in Malaysian public universities by Gan et al. (2019) (12.2\%) and Sarina and Poh (2015) (23.4\%). Meanwhile, compared to the study carried out in the United States, by Yahia et al. (2017), the prevalence of NES (12.3\%) found among the university students was much lower than our finding too. This shows that private university does have a higher prevalence of NES as the prevalence found in this study was higher than the previous studies. This may be because of the different geographical areas, different ethnics distribution, different cultures, and personal habits among private and public university students (Pike and Dunne, 2015). Meantime, the Covid-19 pandemic could be a factor which affects the eating behaviours of the university students as there are huge changes in their daily life such as lack of social life, social distancing, online teaching and new assessment methods (Cao et al., 2020).

As the prevalence of NES among the university students is high, the university should take this issue seriously and take precaution such as rising the awareness by sending emails to all students to discourage eating in the late night. Also, health related department of the university should provide some strategies to tackle the problem of NES. The working hours of the late hour restaurants or convenient stores should be shortened during the night.

\section{The Association Between Night Eating Syndrome and Sleep Quality}

University students generally have poorer sleep quality and inadequate sleep duration (Orzech et al. 2011). In this study, almost half of the students (45.2\%) were poor sleepers. Similar findings were reported by Ngu et al. (2017) and Saat et al. (2020). The prevalence of poor sleep quality among the public universities students in Malaysia were 54\% and 63.9\% respectively. The prevalence of poor sleep quality in this study was lower than the previous studies by $8.8 \%$ and $18.7 \%$. The difference in stress level could be the reason for the different prevalence of poor sleep quality found among the public and private university students. According to Babar et al. (2015), the academic stress level was reported greater among the public university students as compared to private university students.

The stress level was suggested to be positively associated $(\mathrm{r}=0.315, \mathrm{p}<0.01)$ with sleep quality (LopezRodriguez et al., 2017). Meantime, another study by Seun-Fadipe and Mosaku (2017) suggested that the year of study, psychological distress, and depression and anxiety symptoms were the risk factors of poor sleep quality among the students. Al-Kandari et al. (2017) too found that sleep quality is significantly correlated with sleep hygiene practices, which means students lack sleep hygiene practices were more likely to be a poor sleeper. Besides, increased amount of time spent on studying, 
extracurricular activities and social time, and freedom to choose their preferred bedtime, as parental guidance was reduced, could be the possible factors that cause sleep disturbances (Kabrita et al., 2014).

Poor sleep quality which includes sleep-onset insomnia and nocturnal awakening at least 3 times per week with consumption of food on most awakening, was one of the diagnostic factors for NES (Runfola et al., 2014). From our study, students with poorer sleep quality were found to have 1.2 times higher chance to be engaged in NES. This finding is in line with the previous studies by Akdevelioglu et al. (2020) and Farhangi (2019) where the NES patients tend to have poor sleep quality. According to Gan et al. (2019), 19.7\% of the NES group was having poor sleep quality and a significant difference $(\mathrm{p}<0.001)$ was found between the non-NE and NES groups. According to Runfola et al. (2014), poor sleep quality symptoms including insomnia and nocturnal awakening were associated with NES. Meantime, NES in the poor sleepers was significantly greater $(\mathrm{p}=0.03)$ than the good sleep quality group (Farhangi 2019). This shows the sleep quality tends to be poorer as the symptoms of NES increased.

This positive association between poor sleep quality and NES may due to the shorter sleep duration and/or because of the nocturnal ingestion with the NES group (Yahia et al., 2017). A study by Yahia et al. (2017) found that, among the college students, the NES group was associated with higher PSQI score and shorter sleep duration. According to Canuto et al. (2013), the abnormal sleep-wake timing may delay the timing of caloric intake and cause internal circadian desynchrony and poor sleep quality. As the sleep duration is shortened, the individuals will be more likely to get bored and develop the urge to eat something.

\section{The Association between Night Eating Syndrome and Body Mass Index}

Majority of the students from both non-NE and NES groups have normal BMI. However, near 18.1\% of the participants were found to be overweight while near $8 \%$ of the participants were obese. This high prevalence of overweight and obesity $(25.9 \%)$ was similar to the past studies. According to a study by Gopalakrishnan et al. (2012), 14.8\% of the students from AIMST university in Malaysia were found to be overweight and $5.2 \%$ of the students were obese. A total of $23.0 \%$ and $17.6 \%$ of the Bachelor's students from five different universities in Malaysia were found to be overweight and obese (Radzi et al., 2019). Another study by Ghazi et al. (2018) showed that $68 \%$ of the students $(n=178)$ were lack of obesity knowledge. As the rates of overweight and obesity were surprisingly high, the body mass status of the university students should be addressed and monitored carefully, nutrition knowledge should be given and awareness regarding to overweight and obesity should be raised in order to prevent various related health consequences such as cardiovascular disease, hypertension, and stroke (Djalalinia et al., 2015).

The previous studies have supported the result of this study where the NES was found to be positively associated with BMI. NES was found to be associated with weight gain and obesity (Vander Wal, 2012) while a positive association was found between NES and BMI of college and female university students (Meule et al., 2014). A review paper by Bruzas and Allison (2019) found that NES was positively associated with BMI. Logically, the NES can cause one to overeat, thus causing the caloric intake to surpass the daily caloric requirement. This excessive caloric intake thus causes weight gain and so higher BMI. Also, more studies have found that circadian imbalances were related to obesity and this finding indirectly suggests that the relationship between NES and high BMI (obesity) (Gallant et al., 2012).

In contrast, Dzulkafli et al. (2020) found that there was no association between NES and BMI among the female university students while no significant difference was found between the BMI of the adolescent with and without NES (Farhangi, 2019). A different questionnaire used in assessing NES may be a possible reason for the difference in NES prevalence found. Also, as the study by Dzulkafli et al. (2020) focused on female university students, the specification of gender could be a possible explanation. According to Sarina and Poh (2015) and Stunkard (2008), male subjects are more likely to be engaging with NES compared to females. This can also be explained by the greater levels of 
body size dissatisfaction and desire to be thin by females than males (Thompson, 2015). According to Yahia et al. (2011), 89\% of the participants who voted for "extremely worried" about their body image perception were female participants. Thus, females may control their diets to achieve their ideal body shape and hence causing a lower rate of NES.

\section{The Association between Sleep Quality and Body Mass Index}

In this study, a positive association was found between sleep quality and BMI of the university students. This finding was in line with the study by Krističević et al. (2014) which found that poor sleep quality was associated with high BMI (overweight and obesity). High BMI was also found to be related to poor sleep quality in the study by Vargas et al. (2014). According to Spiegel et al. (2004), sleep deprivation was found to be associated with $18 \%$ reduction $(\mathrm{p}=0.04)$ and $23 \%$ increment $(p<0.04)$ of the anorexigenic hormone leptin and orexigenic factor ghrelin respectively, $24 \%$ increment of hunger $(\mathrm{p}<0.01)$ and $23 \%$ increment of appetite $(\mathrm{p}=0.01)$. These findings indicated that poor sleep quality such as short sleep duration was associated with an increment in the urge to eat, causing excessive energy intake and therefore leading to overweight or obesity.

Contradictorily, a study by Lai and Say (2012) found that the BMI of university students in Malaysia was not associated with total sleep duration and PSQI. No significant difference was found between the sleep duration of participants from different BMI classes too. This may due to the inaccuracies in the self-reported anthropometric measurements of the participants. Other factors such as insufficient energy intake and high level of physical activity can be the possible reason for the mixed findings, specifically no relationship between sleep quality and BMI.

\section{Factors Associated with NES among the university students}

Furthermore, after adjusted with the related variables, gender and PSQI were found to be the risk factors for NES. A study in Malaysia by Gan et al. (2019) found that males have a 3 times higher chance to be engaged with NES than females. A study by Suh et al. (2012) found that males were 1.9 times more likely to be engaged with NES than females while another study by He et al. (2018) found that male university students show a higher prevalence of NES than female students too. Our finding is consistent with these previous findings where males were suggested to have a 2 times higher risk to be engaged in NES than the females. This could be explained as females were more concerned about overeating, overweight and body shape compared to males (Pike and Dunne, 2015; Yahia et al., 2011), so they tended to avoid eating at night and hence were protected from NES.

Besides, NES among the university students was possibly caused by the diversity of participants' socio-demographic characteristics, culture, and degree of urbanization which could influence the participants' behaviour and daily habits (Pike and Dunne, 2015). Also, this difference in results can be caused by different local food environments and the availability of the late hour restaurant (Gan et al., 2019). The eveningness chronotype of the individuals can cause NES (Riccobono et al., 2019). Due to the delayed circadian rhythm and sleep phase, the awakening time and first meal time will be delayed too, thus defer the dinner time to the late night. Meantime, this could be partly due to food addiction. According to Nolan and Geliebter (2017), although food addiction was not considered as a diagnostic criterion for NES, the severity of NES symptoms was associated with food addiction. Food addiction can cause one to overeat and was found to be associated with some neuropsychiatric problems including poor sleep quality (Najem et al., 2020).

\section{Conclusion}

In conclusion, the prevalence of night eating syndrome, poor sleep quality, overweight and obesity among the university students were all at alarming rates during the Covid-19. In particular, NES was found to be related to a higher prevalence of overweight, obesity and poor sleep quality while poor sleep quality was found to be positively related to NES and higher BMI among the students. Meanwhile, males and students with poorer sleep quality were found to be at higher risk of NES than 
females and good sleepers. This unhealthy eating behaviour should be taken more seriously as poor sleep quality and high BMI can lead to various negative health consequences in the long term. In this case, the government and the university authorities play a crucial role in raising awareness of this eating disorder. Students should also start to develop awareness of NES and take control of their food consumption and eating behaviour. In the case if this eating behaviour is severe, students should consult with a nutritionist or dietitian for some targeted interventions and strategies to aid in tackling NES. More studies should be conducted in the future to include the calorie intake of the students especially what food are eaten in the evening and during the night and the quality of the food to have a better understanding on the dietary intake in university students with NES.

\section{References}

Akdevelioglu Y., Sahin T. O., Yesildemir O. (2020). Sleep quality and its relationship with night eating syndrome, the risk of diabetes, and nutritional status among university students. Progress in Nutrition 22(1):304-315.

Al-Kandari S., Alsalem A., Al-Mutairi S., Al-Lumai D., Dawoud A., Moussa M. (2017). Association between sleep hygiene awareness and practice with sleep quality among Kuwait University students. Sleep Health 3(5):342-347.

Allison K. C., Lundgren J. D., O'Reardon J. P., Martino N. S., Sarwer D. B., Wadden T. A., Crosby R. D., Engel S. G., Stunkard A. J. (2008). The Night Eating Questionnaire (NEQ): Psychometric properties of a measure of severity of the Night Eating Syndrome. Eating Behaviours 9(1):6272.

Allison K.C., Lundgren J.D., O'Reardon J. P., Geliebter A., Gluck M. E., Vinai P., Mitchell J. E., Schenck C. H., Howell M. J., Crow S. J., Engel S., Latzer Y., Tzischinsky O., Mahowald M. W., Stunkard A. J. (2010). Proposed diagnostic criteria for night eating syndrome. International Journal of Eating Disorders 43(3):241-247.

Babar M. G., Hasan S. S., Ooi Y. J., Ahmed S. I., Wong P. S., Ahmad S. F., MNM-Rosdy N. M., Malik N. A. (2015). Perceived sources of stress among Malaysian dental students. International Journal Of Medical Education 6:56-61.

Birketvedt G. S., Florholmen J., Sundsfjord J., Osterud B., Dinges D., Bilker W., Stunkard A. (1999). Behavioral and neuroendocrine characteristics of the night-eating syndrome. JAMA, 282, pp. 657-663.

Buysse D. J., Reynolds III, C. F., Monk T. H., Berman S. R., Kupfer D. J. (1989). The

Pittsburgh sleep quality index: A new instrument for psychiatric practice and research. Psychiatry Research 28(2):193-213.

Bruzas M. B., Allison K. C. (2019). A Review of the Relationship between Night Eating Syndrome and Body Mass Index. Psychological Issues 8:145-155.

Cao W., Fang Z., Hou G., Han M., Xu X., Dong J., Zheng J. (2020) The psychological impact of the COVID-19 epidemic on college students in China. J. Psychiatry Res. 287, 112934.

Cheng S-H. \& Mohd Kamil, M.K (2020). Stress and food intake among university students - is there a relationship? Sains Malaysiana 49(1):121-128.

Canuto R., Garcez A. S., Olinto M. T. A. (2013). Metabolic syndrome and shift work: a

systematic review. Sleep Med Rev. 17(6):425-431.

Daniel W. W., Cross C. L. (1999). Biostatistics: A Foundation for Analysis in the Health Sciences. $7^{\text {th }}$ edn. New York: John Wiley \& Sons.

Dietch J. R., Taylor D. J., Sethi K., Kelly K., Bramoweth A. D., Roane B. M. (2016).

Psychometric Evaluation of the PSQi in U.S. College Students. J Clin Sleep Med 12(8):1121-1129.

Djalalinia, S., Qorbani, M., Peykari N., Kelishadi R. (2015). Health Impacts Of Obesity. Pak J Med Sci 31:239-242.

Dzulkafli N. H., Hamirudin A. H., Sidek S. (2020). Night Eating Syndrome and its Association with Body Mass Index among Female University Students. International Journal of Allied Health Sciences 4(4):1626-1634.

Farhangi M. A. (2019). Night Eating Syndrome and Its Relationship with Emotional Eating, Sleep Quality and Nutritional Status Among Adolescents' Boys. Community Mental Health Journal 55:1411-1418. 
Gallant A. R., Lundgren J., Drapeau V. (2012). The night-eating syndrome and obesity. Obesity Reviews 13(6):528-536.

Gan W. Y., Chin P. Q., Law L. S. (2019). Determination of Risk Factors for Night Eating Syndrome among Public University Students in Malaysia. Malaysian Journal of Medicine and Health Science 15(SP1):25-32.

Gopalakrishnan S., Ganeshkumar P., Prakash M. V. S., Christopher, Amalraj V. (2012).

Prevalence of overweight/obesity among the medical students, Malaysia. The Medical Journal of Malaysia 67(4):442-444.

Ghazi H. F., Abdalqader M. A., Baobaid M. F., Hasan T. N., Alabed A. A. A., Veerabadran V., Abdalrazak H. A., Gazi T. M., Hassan M. R., (2018). Obesity Knowledge and its Associated Factors among Medical Students in a Private University in Shah Alam, Selangor. Malaysian Journal of Public Health Medicine 18(2):45-51.

Gluck M. E., Geliebter A., Satov T. (2001). Night Eating Syndrome Is Associated with

Depression, Low Self-Esteem, Reduced Daytime Hunger, and Less Weight Loss in Obese Outpatients. Obesity Research 9:264-267.

He J., Huang F., Yan J., Wu W., Cai Z., Fan X. (2018). Prevalence, demographic correlates, and association with psychological distress of night eating syndrome among Chinese college students. Psychology, Health \& Medicine 23(5):578-584.

Kabrita C. S., Hajjar-Muca T. A., Duffy J. (2014). Predictors of poor sleep quality among Lebanese university students: association between evening typology, lifestyle behaviors, and sleep habits. Nat Sci Sleep 6:11-18.

Krističević T., Štefan L., Sporiš G. (2014). The Association between Sleep Duration and Sleep Quality with Body-Mass Index in a Large Sample of Young Adults. International Journal of Environmental Research and Public Health 15(4):758.

Lai P.-P., Say Y.-H. (2012). Associated Factors of Sleep Quality and Behaviour among

Students of Two Tertiary Institutions in Northern Malaysia. Med J Malaysia 68(3)195-202.

Lundgren J. D., Allison K. C., Vinai P., Gluck M. E. (2012). Assessment instruments for night eating syndrome. In J. D. Lundgren, K. C. Allison, \& A. J. Stunkard, eds, Night eating syndrome: Research, assessment, and treatment (2012). New York: Guilford Press, pp. 197-217.

Meule A., Allison K. C., Platte P. (2014). A German version of the Night Eating Questionnaire (NEQ): psychometric properties and correlates in a student sample. Eat Behav 15(4):523-527.

Najem J., Saber M., Aoun C., Osta N. E., Papazian T., Khabbaz L. R. (2020). Prevalence of food addiction and association with stress, sleep quality and chronotype: A cross-sectional survey among university students. Clinical Nutrition 39(2):533-539.

Nolan L. J., Geliebter A. (2016). "Food addiction" is associated with night eating severity.Appetite 98:89-94.

Nolan, L. J., Geliebter A. (2017). Validation of the Night Eating Diagnostic Questionnaire (NEDQ) and its relationship with depression, sleep quality, "food addiction", and body mass index. Appetite 111:86-95.

Ngu S. T., Masalamany K., Manan N. A., Adam S. K. (2017). Sleep Quality among Pre-Clinical Medical Students in Universiti Putra Malaysia and University Malaya, Malaysia. Education in Medicine Journal 9(3):23-31.

Orzech K. M., Salafsky D. B., Hamilton L. A. (2011). The state of sleep among college students at a large public university. J Am Coll Health 59(7):612-619.

Pike K. M., Dunne P. E. (2015). The rise of eating disorders in Asia: a review. Journal of Eating Disorders 3(33).

Radzi C. W. J. W. M., Jenatabadi H. S., Alanzi A. R. A., Mokhtar M. I., Mamat M. Z., Abdullah N. A., (2019). Analysis of Obesity among Malaysian University Students: A Combination Study with the Application of Bayesian Structural Equation Modelling and Pearson Correlation. International Journal of Environment Research and Public Health 16(3):492.

Riccobono G., Pompili A., Iannitelli A., Pacitti F. (2019). The relationship between Night-Eating Syndrome, depression and chronotype in a non-clinical adolescent population. Riv Psichiatr. 54(3):115-119.

Runfola C. D., Allison K. C., Hardy K. K., Lock J., Peebles R. (2014). Prevalence and clinical significance of night eating syndrome in university students. Journal of Adolescent Health 55(1):41-48. 
Saat N.Z.M., Hanawi S. A., Chan K. S., Hanafiah H., The S. C., Aznan S. R., Joan C A. S., Zulkefli Z. H. (2020). Sleep Quality among University Students: Association between Demographic Factors and Physical Activity Level. International Journal of Pharmaceutical Research \& Allied Sciences 9(3):57-65.

Sarina S., Poh L. K. (2015). Association between Socio-demographic Status and Body Mass Index with Night Eating Syndrome among University Students in Shah Alam, Selangor, Malaysia. Malaysia Journal of Nutrition 21.

Suh Y., Lee E. k., Chung Y. J. (2012). Comparison of nutritional status by energy level of night snack in Korean adults: using the data from 2005 Korean National Health and Nutrition Examination Survey. The Korean Journal of Nutrition 45(5):479-488.

Shillito, J. A., Lea, J., Tierney S., Cleator J., Tai S., Wilding J. P. H. (2018). Why I eat at night: A qualitative exploration of the development, maintenance and consequences of Night Eating Syndrome. Appetite 125:270-277.

Spiegel K., Tasali E., Penev P., Cauter E. V. (2004). Brief Communication: Sleep Curtailment in Healthy Young Men Is Associated with Decreased Leptin Levels, Elevated Ghrelin Levels, and Increased Hunger and Appetite. Annals of internal medicine 141(11):846-850.

Stunkard, A. J., Grace, W.J., Wolff H. G. (1955). The night-eating syndrome. A pattern of food intake among certain obese patients. American Journal of Medicine 19:78-86.

Stunkard A. J. (1992). Obesity. In R. Berkow, A. J. Fletcher, eds. The Merck Manual of

Diagnosis and Therapy. Rahway, NJ: Merck Research Laboratories, pp. 981-986.

Stunkard A. J. (2008). The Night Eating Questionnaire (NEQ): Psychometric properties of a measure of severity of the night eating syndrome. Eat Behav 9:62-72.

Thompson, S. (2015). Gender And Racial Differences In Emotional Eating, Food Addiction Symptoms, And Body Weight Satisfaction Among Undergraduates. Journal Of Diabetes And Obesity 2:1-6.

Vander Wal J. S. (2012). Night eating syndrome. Clinical Psychology Review 32(1):49-59.

Vargas P. A., Flores M., Robles E. (2014). Sleep Quality and Body Mass Index in College Students: The Role of Sleep Disturbances. Journal of American College Health 62(8):534-541.

World Health Organization (2004). Appropriate body-mass index for Asian populations and its implications for policy and intervention strategies. The Lancet 363:157-163.

Yahia N., El-Ghazale H., Achkar A., Rizk S. (2011). Dieting practices and body image

perception among Lebanese university students. Asia Pacific journal of clinical nutrition 20(1):21-28.

Yahia N., Brown C., Potter S., Szymanski H., Smith K., Pringle L., Herman C., Uribe M., Fu Z., Chung M., Geliebter A. (2017). Night eating syndrome and its association with weight status, physical activity, eating habits, smoking status, and sleep patterns among college students. Eat Weight Disord. 22(3):433. 